\title{
Networking
}

\section{Getting primary care research published: the experience of the WeLReN writers' support group}

Paul Thomas Applied Research Unit, Brent Primary Care Trust, Wembley Centre for Health and Care, Chaplin Rd, Wembley, HA0 4UZ and Tim Albert Principal of Tim Albert Training, Paper Mews Court, 284 High Street, Dorking, Surrey RH4 10T

The West London Research Group (WeLReN) was one of many primary care research networks (Thomas et al, 2001) set up in the late 1990s to 'achieve an evidence based culture in primary care' (NHSE, 1997). For the first three years WeLReN devoted its resources to facilitating good quality research of relevance to local primary care. A sequence of courses was developed for novice researchers to learn about research methods, presentation skills, writing skills and how to use research to stimulate the development of local primary care. However, at the end of the three years only six of the 31 projects supported had resulted in a peer reviewed publication. The WeLReN planning group therefore decided that an additional intervention was needed to give impetus to the actual writing process. This paper describes this intervention, which took the form of a writers group.

\section{Description of the programme}

A meeting was held in July 2001 between WeLReN and Tim Albert Training (see Note). They agreed to set up a 'fast track publications group' (subsequently dubbed the 'WeLReN All Stars') to develop and support writing skills, using an approach that focuses on the writing process, from key message through planning and writing to rewriting and negotiating with co-authors and preparing the final submission (Albert, 2000).

Tim Albert Training was founded in 1990 and has developed a range of writing skills courses for health professionals. Tim Albert is course director of the BMJ/Blackwells annual short course for medical journal editors, now in its seventh year.
There were two criteria for eligibility: participants had to have attended at least one of the one-day writing courses previously offered by WeLReN, and they had to have completed the collection of their data. Six people signed up for the 15 -week programme, of whom two were general practitioners, two were primary care facilitators/ managers, one was a consultant psychiatrist and one was a community psychologist. The goal was to have four articles published by December 31, 2002.

The course started on November 27, 2001 and at the first meeting participants agreed the target of 10 articles sent off within 15 weeks. They also discussed the messages of their papers and identified suitable target journals. Only one participant had funded time to do the writing. At a meeting in week seven, participants brought their first draft, and discussed macro-editing issues. At week 11 they brought their revised drafts, and discussed problems they were facing. At week 15 a celebratory lunch was held to congratulate those who had sent papers off and to encourage the others. The emphasis throughout was on helping each member to maintain progress. The course leader (TA) acted as facilitator and maintained a progress chart which was circulated and updated electronically. Between weeks 15 and 21 he continued by e-mail to encourage the writers to complete their papers.

\section{Results and feedback}

At the group's deadline of 15 weeks two authors had sent off a total of three articles (see Table 1). After 21 weeks four of the six participants had sent 
Table 1 Progress towards submission of articles

\begin{tabular}{llll}
\hline Participant & 15 week target & 15 week actual & 21 week actual \\
\hline A & Article sent off & - & - \\
A & Article sent off & - & - \\
B & Article sent off & Article sent off & - \\
B & Article sent off & Article sent off & With co-authors \\
B & Article sent off & In draft & - \\
C & Article sent off & Article sent off & In draft \\
$D$ & Article sent off & In draft & Co-authors veto \\
$D$ & Article sent off & In draft & Article sent off \\
E & Article sent off & In draft & Article sent off \\
E/F & Article sent off & In draft & In draft \\
$G * / B$ & - & Idea for article & \\
\hline
\end{tabular}

* Facilitator

off a total of six articles, and a further paper (this one) was being finalised by the facilitator and one of the participants. The fifth author reported that their first paper was in draft and an informal approach made to an editor; the second had been written and sent to co-authors, who had recommended that it be split into two papers instead. The sixth member, a primary care manager, who had planned to write two papers, withdrew from the programme after the first session because of pressure of work.

Participants were e-mailed for comments on the scheme. They cited three main strengths: the imposition of deadlines, the support of the rest of the group, and the expertise of the facilitator. Weaknesses included the difficulties the practitioners had in finding protected time (all but one continued a clinical commitment at a time of fast change in primary care), the need for guidance about writing formats other than IMRAD (Introduction, Methods, Results, Discussion), and the need for some critical appraisal. The group recommended that this set of courses should become a regular part of the research calendar of the primary care research network.

\section{Discussion}

The intention that six people could complete 10 papers in 15 weeks turned out to be ambitious. However, six papers were completed within 21 weeks. The reasons stated informally by the two participants who did not complete their papers were lack of time, lack of confidence, and differences with co-authors. All those who took part, however, increased their understanding of the required writing skills, and in particular accepted the need to focus less on the 'science' of the research project and more on the 'art' of explaining their findings to a wider audience.

WeLReN has now decided to put a greater emphasis on writing at every stage of its research cycle. It will continue to offer an initial one-day course on writing skills early in the life of a research project and then run a support group when the data has been gathered. Thus each year the network can rely on a new cohort of researchers to disseminate research findings through publications. The preconditions and general format will remain unchanged, but the participants will be asked to give a commitment in advance that they will attend all meetings. Co-authors will be informed of the project, and asked to agree the message and target journal at the start of the course.

The overall conclusion is that primary care research is more likely to be published if researchers are supported to learn about the publication process with facilitated support to meet writing deadlines. Primary care research networks are well placed to provide this.

\section{References}

Albert, T. 2000: Winning the publications game (2nd edition), Abingdon: Radcliffe Medical Press.

NHS Executive 1997: $R \& D$ in primary care: Report of a Working Group. (Chair D. Mant). Department of Health, London.

Thomas, P., Griffiths, F., Kai, J., and O'Dwyer, A. 2001: Networks for research in primary health care. British Medical Journal 322, 588-590. 